\title{
C7 radiculopathy: importance of scapular winging in clinical diagnosis
}

\author{
GJV MAKIN, WF BROWN, GCEBERS \\ From the Department of Clinical Neurological Sciences, University of Western Ontario, London, Ontario, \\ Canada
}

SUMMARY Lesions of the seventh cervical (C7) root are common and cause a readily recognised neurological syndrome. Recognition of this pattern is essential in differentiating $\mathrm{C} 7$ root lesions from lesions of the brachial plexus or peripheral nerves. Serratus anterior weakness is not generally included in this syndrome. We report six verified cases of $\mathrm{C} 7$ radiculopathy in which weakness of the serratus anterior was present in addition to the usual findings. This was manifest as winging of the scapula, when pushing forward against a wall, either with the hands at shoulder level or, in some cases, only when the hands were lowered to waist level. This latter method of testing places the muscle at a mechanical disadvantage and reveals partial paralysis. Analysis of this clinical finding complements anatomical evidence suggesting that the powerful lower digitations of the muscle may be primarily supplied by the $\mathrm{C} 7$ root in some cases. Scapular winging, apparent either in the usual position or the modified position described here, should be recognised as consistent with a diagnosis of $\mathrm{C} 7$ radiculopathy. When present, this sign serves to differentiate $\mathrm{C} 7$ radiculopathy from lesions of the brachial plexus or radial nerve.

Lesions of the seventh cervical nerve root are common and may be recognised by a characteristic, though somewhat variable, pattern of motor, sensory and reflex impairment. Weakness of the serratus anterior has not generally been an accepted part of the $\mathrm{C} 7$ root syndrome. ${ }^{1-4}$ We describe six cases of $\mathrm{C} 7$ radiculopathy in which this finding was apparent. In two, scapular winging was prominent and initially led to the incorrect diagnosis of neuralgic amyotrophy. In four others, the finding was only apparent when specifically sought, using a method of muscle testing which places the serratus anterior at a mechanical disadvantage. In addition to the clinical usefulness of recognising this phenomenon, its occurrence complements anatomical evidence suggesting topographic innervation of the serratus anterior

\section{Case histories}

In each of the following case histories, an exact diagnosis has been possible either through direct surgical verification of a C6/7 disc herniation with $\mathrm{C} 7$ root compression (five cases), or by combined metrizimide myelography and computed

Address for reprint requests: GC Ebers, Department of Clinical Neurological Sciences, University Hospital, London, Ontario, Canada N6A 5A5.

Received 30 August 1985. Accepted 10 October 1985 tomography (1 case). Clinical details have therefore been edited for brevity. Because the diagnosis in each case is unequivocal, relatively minor departures from the textbook description of $\mathrm{C} 7$ radiculopathy serve only to emphasise the clinical and laboratory variability of this syndrome.

\section{Case 1}

A 48 year-old-painter, presented with a 10 week history of right shoulder and arm pain exacerbated by straining, coughing and by turning the head to the left. Examination demonstrated weakness of triceps, pectoralis major and extensor carpi ulnaris. Numbness with loss of pinprick sensation over the second and third digits and loss of the triceps reflex completed a pattern felt to be most likely due to $\mathrm{C} 7$ root irritation. Serratus anterior weakness was manifest as winging of the scapula on pushing forward against a wall. This occurred only when the hands were at waist level and was abolished in the more usual position with the arms horizontal and the hands at shoulder level (fig 1A and B). A C6/7 disc herniation, with obliteration of the nerve root sleeve, was demonstrated on metrizimide myelography. Anterior discectomy and fusion at the C6/7 level was carried out, during which the right $\mathrm{C} 7$ root was seen to be compressed. Complete relief of symptoms and eventual return of strength in affected muscles ensued. In particular, serratus anterior weakness could no longer be demonstrated in any position.

Case 2

A 32-year-old secretary, had a five month history of scapular and neck pain radiating down the posterolateral arm into 

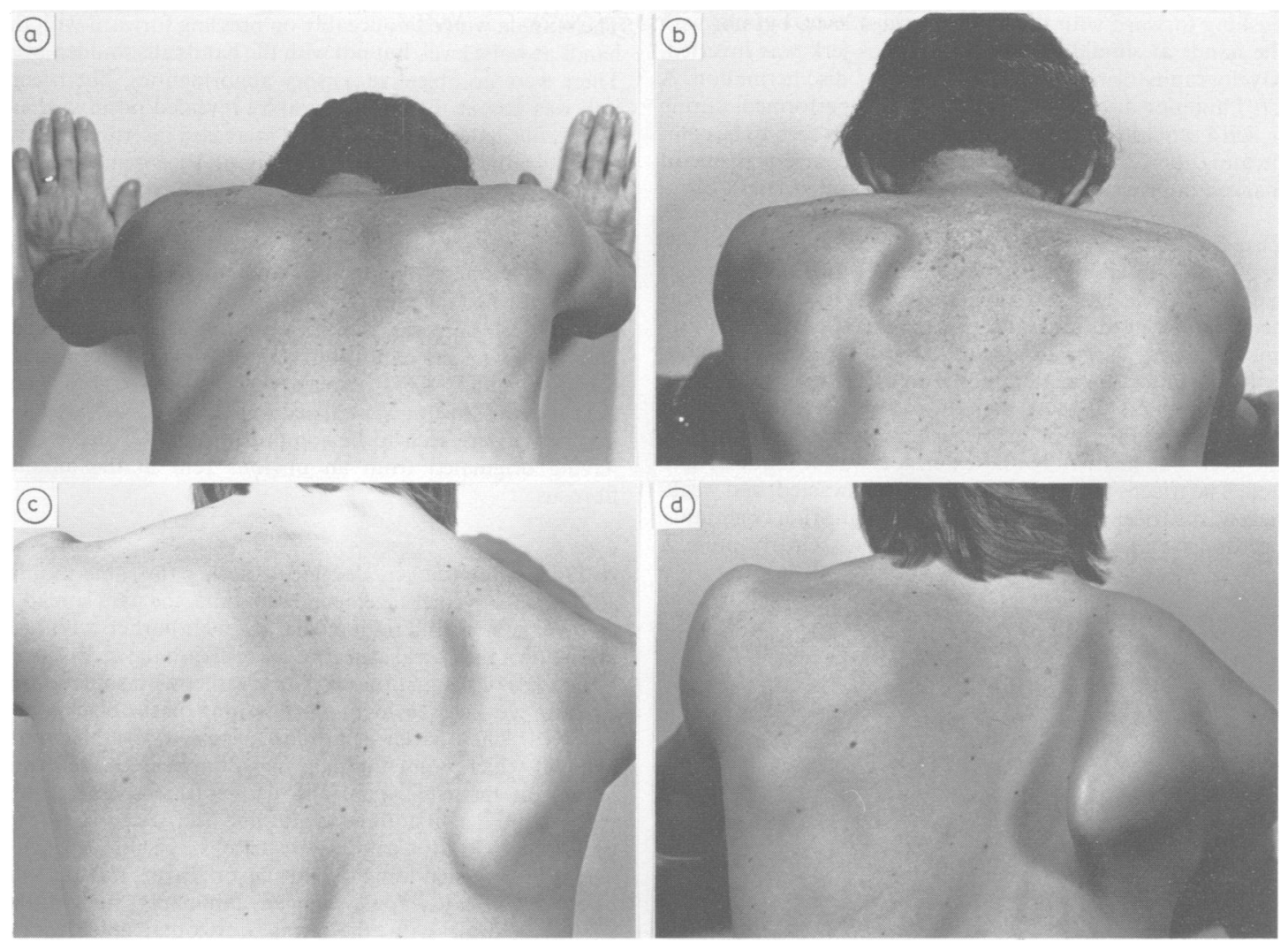

Fig 1, A and B Case 1, showing scapular winging present on pushing forward against a wall. This is seen only when the hands are lowered to waist level (B), thus placing serratus anterior at a mechanical disadvantage. C and D Scapular winging in this young man with an idiopathic long thoracic nerve palsy is manifest in both arm positions but is also accentuated with the hands at waist level.

the second and third digits. Paraesthesiae and, later, numbness also affected these fingers. The triceps muscle was wasted and weak, with weakness also in the pectoralis major, latissimus dorsi and extensor carpi ulnaris. Pinprick sensation was reduced in the second and third digits and up the posterolateral aspect of the forearm. The triceps jerk was reduced. Marked winging of the scapula, again seen only on forward pushing with the hands at waist level, was present. Denervation potentials were present in the triceps, extensor carpi ulnaris and eighth digitation of serratus anterior. Myelography demonstrated a $\mathrm{C6} / 7$ disc protrusion with $\mathrm{C} 7$ root compression, and $\mathrm{C6/7}$ anterior discectomy and fusion was carried out. The $\mathrm{C} 7$ root was seen to be compressed by a sequestrated disc fragment. All weak muscles, including the serratus anterior eventually regained their normal strength and only minimal sensory deficits persisted.

\section{Case 3}

A 34-year-old woman developed persistent right scapular pain with paraesthesiae in the thumb, index and middle fingers. Later, the pain radiated down the dorsolateral aspect of the arm as far as the wrist. Examination disclosed marked weakness of triceps and latissimus, with a lesser degree of impairment of extensor carpi ulnaris. There was marked scapular winging with the arms extended, accentuated by pushing forward against a wall. No objective sensory loss could be detected but the triceps jerk was diminished. The scapular winging was initially felt to rule out C7 radiculopathy, and a clinical diagnosis of neuralgic amyotrophy was made. Myelography (Pantopaque ${ }^{R}$ ) demonstrated a $\mathrm{C} 6 / 7$ disc herniation with splaying of the nerve roots. At $\mathrm{C} 6 / 7$ discectomy a disc fragment was removed from the $\mathrm{C} 7$ root canal, relieving obvious compression of the $\mathrm{C} 7$ root. Symptomatic relief and full return of strength were present within days of operation.

\section{Case 4}

A 42-year-old housewife had experienced neck, shoulder and right arm pain for five weeks. The pain radiated down the dorsolateral aspect of the arm into the third digit, particularly when the head was rotated to the right. Numbness and paraesthesiae of the first three digits was present, with a corresponding area of reduction in pain sensation on examination. The forearm was slightly wasted; mild weakness of shoulder adductors, triceps, extensor digitorum communis, and supinator was present. The scapula winged markedly on 
pushing forward with the hands at waist level, but not with the hands at shoulder level. The triceps jerk was inverted. Myelography demonstrated a large C6/7 disc herniation. A C6/7 anterior discectomy and fusion was performed, during which a sequestrum of nucleus pulposus was seen to be compressing the $\mathrm{C} 7$ root. The postoperative course was one of marked improvement in symptoms and arm strength.

\section{Case 5}

A 39-year-old labourer, awoke one day with interscapular pain which subsequently spread to include the left side of the neck, left pectoral area and posterolateral part of the arm and forearm. Neck extension consistently evoked paraesthesiae in the dorsolateral forearm and lateral three digits. Mild numbness of these digits was also present as well as subjective weakness of elbow extension. On examination, the neck was held stiffly and extension was voluntarily limited. The triceps and latissimus dorsi were wasted, and weakness of the triceps, supinator, extensor digitorum communis, pectoralis major and latissimus dorsi was clearly present.
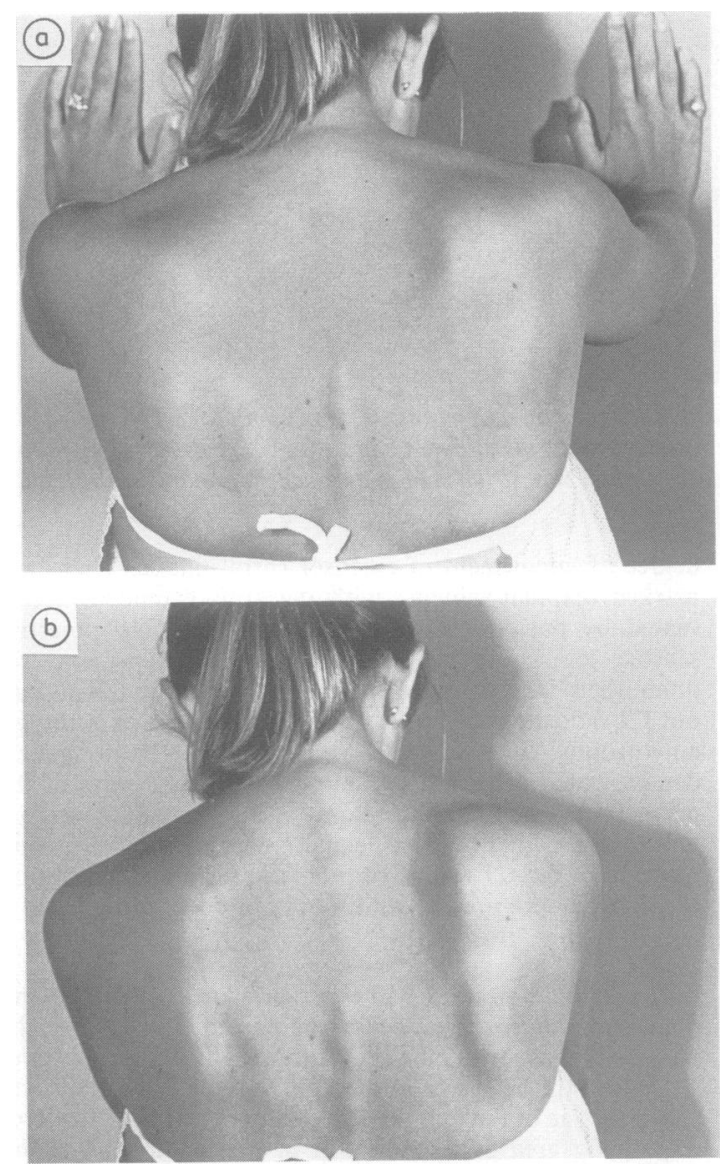

Fig 2, A and B Case 3, showing minimal scapular winging when pushing forward with the arms horizontal, markedly accentuated with the hands lowered to waist level.
The scapula winged noticeably on pressing forward with the hands at waist level, but not with the hands at shoulder level. There were no objective sensory abnormalities. The triceps jerk was absent. Electromyography revealed positive sharp waves, fibrillation potentials and increased insertional activity in serratus anterior (sixth digitation), triceps and extensor digitorum communis. Peripheral sensory conduction in the C7 root distribution was normal. More detailed examination of individual serratus anterior digitations was limited by patient tolerance. Myelography and computed tomography both confirmed the presence of a C6/7 disc herniation. Interestingly, his pain was abolished for several hours immediately following the removal of approximately $10 \mathrm{ml}$ of cerebrospinal fluid. C6/7 anterior cervical discectomy and intervertebral fusion was carried out. Two sequestrated disc fragments were seen to be compressing the C7 nerve root, having originated from an obvious rent in the annulus fibrosus.

\section{Case 6}

A 29-year-old teacher, developed neck pain some months after a motor vehicle accident. With time, the pain spread to involve the neck and right medial scapular border, with radiation down the dorsal aspect of the arm into the index finger. Numbness of the first three digits together with some subjective arm weakness, evident when writing on the blackboard, followed. These latter symptoms persisted several months later, at which point the pain had disappeared. On examination at this time, pain and temperature sensation waso reduced in the first three digits and the triceps jerk wast diminished. Mild weakness of triceps, pectoralis major $\frac{\varrho}{\mathbb{D}}$ extensor pollicus longus and flexor carpi radialis wå detectable. The scapula winged minimally on pushing against a wall with the arms horizontal, but winged markedly with the hands at waist level (fig 2). EMG was

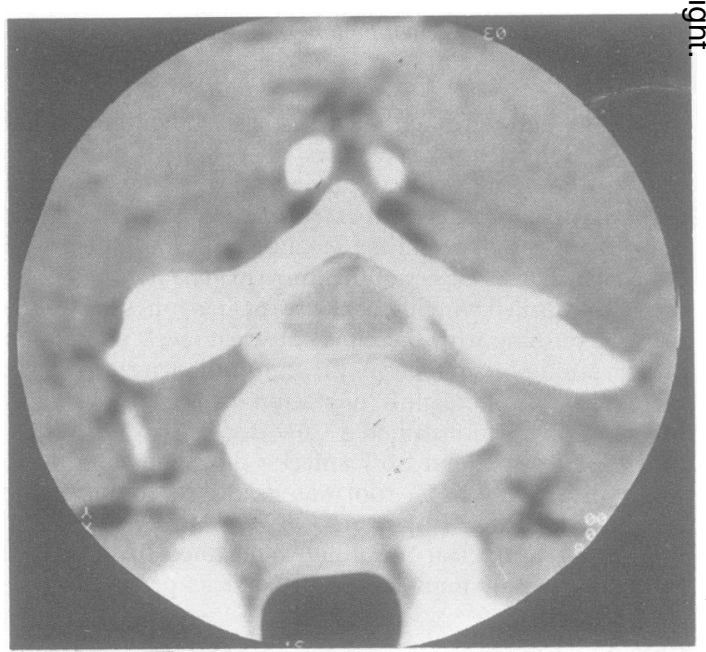

Fig 3 Computed tomographic scan through the C6/7 intervertebral disc in patient Case 3. Metrizimide is present in the subarachnoid space. An unequivocal posterolateral disc protrusion is evident on the right. Routine myelography was normal. 
normal. Although metrizimide myelography was normal, a computed tomographic scan through the C6/7 disc demonstrated an unequivocal posterolateral disc protrusion (fig 3 ). At the time of writing, no surgery has been required.

\section{Discussion}

C7 root compression was unequivocally proven as the sole abnormality in each of our six patients. In each case a constellation of symptoms and signs typical of this disorder was present, but in addition there was clinically evident weakness of serratus anterior. This confirms that serratus anterior must be included amongst those muscles affected in $\mathrm{C} 7$ radiculopathies, and that its involvement does not necessarily imply an alternate diagnosis such as neuralgic amyotrophy. ${ }^{5-7}$ Such weakness may be prominent (as in long thoracic nerve injuries) or subtle and seen only when the muscle is placed at a mechanical disadvantage, as discussed below.

The serratus anterior arises in distinct digitations from the upper eight or nine ribs and courses posteriorly to insert upon the anterior aspect of the medial border of the scapula. There is a trend toward the concentration of insertions on certain parts of the scapula, thus leading to the possibility of distinct functional units. While the upper three digitations usually insert on the superior angle of the scapula, the lower five converge on the inferior angle and constitute the most powerful group. ${ }^{8}$ The muscle is important in normal shoulder functioning and its actions may be divided into three categories. Firstly, it fixes the scapula to the chest wall during such actions as pushing, punching and breathing deeply with the aid of pectoralis minor ${ }^{89}$ Secondly, the muscle actively protracts the scapula over the thoracic cage and brings the entire shoulder forward by an action at the sternoclavicular joint, ${ }^{10}$ such as occurs in reaching forward. Together with trapezius and possibly also pectoralis minor, ${ }^{9}$ it rotates the scapula during the second stage of arm abduction. ${ }^{11}{ }^{12}$ In a related action the muscle counters the rotational force transmitted to the scapula by the biceps and coracobrachialis tendons when the arm is held extended or abducted. ${ }^{13}$ The ingenious mechanisms by which the scapulothoracic joint is moved in conjunction with the glenohumeral joint require almost continual modulation of serratus anterior activity.

The serratus anterior, like the diaphragm, is an example of a muscle which migrates during embryogenesis, taking its nerve supply with it. ${ }^{8}$ Motor neurons extend from its ancestral spinal level to the muscle's final position via the long thoracic nerve (external respiratory nerve of Bell, posterior thoracic nerve). A review of several sources reveals the spinal root contributions to be C5, 6 and 7 in most instances. $^{914-19}$ Some authors would minimise the C5 contribution ${ }^{19}$ or include a minor contribution from C8. ${ }^{2021}$ Haymaker and Woodhall state, without evidence, that $\mathrm{C} 7$ supplies primarily the lower digitations of the muscle. ${ }^{9}$ Some support for this contention comes from the work of Horwitz and Tocantins, who dissected 100 long thoracic nerves. ${ }^{22}$ They found that in $92 \%$ of cases a major $\mathrm{C} 7$ contribution was present, which usually joined the nerve only after the C5 and C6 twigs had passed through the scalenus medius, and after branches to the upper two or three digitations had already arisen. Furthermore, in one instance the $\mathrm{C} 7$ contribution proceeded independently to the lower digitations of the muscle, never joining up with the other twigs. In at least 5\% of cases, the C5 contribution also more or less independently supplied the upper digitations. It therefore seems likely, on anatomical grounds, that the lower digitations of serratus anterior are predominantly supplied by the $\mathrm{C} 7$ nerve root. We are unaware of any previous clinical correlations with this anatomical demonstration of probable topographic innervation of serratus anterior, with the possible exception of Overpeck's interpretation ${ }^{12}$ of Potts' case report. ${ }^{11}$ Other collateral sources of innervation, though not of direct relevance to our cases, include a twig to the upper digitations from the dorsal scapular nerve, ${ }^{18}$ and small contributions to the lower digitations from the corresponding intercostal nerves. ${ }^{22} 23$

Our observations may provide the clinical correlation to these anatomical facts. The scapula may be considered as a bony plate, the posterior displacement of which is prevented by a number of different muscles. Chief amongst these is serratus anterior, which binds the medial scapular border to the chest wall. Any force tending to displace the scapula posteriorly, such as that transmitted to the glenoid cavity when leaning on the outstretched arms, will be met by counterforce primarily generated by serratus anterior. If the entire serratus anterior is paralysed, the medial scapular border will wing markedly (fig $1 C$ and D). If, however, only the lower digitations (that is what may be a C7-innervated lower functional group) are paralysed, then the upper digitations may or may not be sufficient to the task of preventing winging. Lowering the arms causes the line of action of the applied force to be displaced from the primary line of action of the upper functional group of digitations, thus placing the remaining muscle at a mechanical disadvantage. In this way, partial lesions of serrratus anterior may be detected by the observation of scapular winging when the displacing force is out of the primary line of action of the remaining functional muscle. The $\mathrm{C} 5$ and $\mathrm{C6}$ roots also help supply serratus anterior, but their contribution may not be as functionally significant. Indeed, patients in whom both the C5 and 
C6 roots have been traumatically avulsed may have a functional serratus anterior (although testing the muscle with the sensitive method described in this report was probably not attempted). ${ }^{24}$ Further observation for scapular winging in selective lesions of these roots may help to clarify this issue.

This concept of topographic innervation of large multisegmental muscles is in keeping with the accepted structure of the neuromuscular system in general.

In conclusion, scapular winging may be a feature of C7 radiculopathy in some patients and should not be misleading when present. When present, it serves to exclude lesions of the brachial plexus or radial nerve. Winging may be evident only when pushing forward with the hands at waist level. This sign may reflect selective weakness of the lower digitations of serratus anterior, such as might be anticipated from anatomic evidence to be the case in $\mathbf{C} 7$ radiculopathy.

We are grateful to Dr A Kleider of Sioux City, Iowa, for bringing to our attention two further cases of scapular winging in $\mathrm{C} 7$ radiculopathy (both apparent only in the modified testing position), and to $\mathrm{Dr}$ HWK Barr for permission to study his patient and be present at operation. Drs PE Cooper, J Girvin and GC Ferguson have also kindly allowed us to study their patients. We are indebted to Mrs Carole Sutherland for assistance in preparing the manuscript.

\section{References}

${ }^{1}$ Sunderland S. In: Sunderland S. Nerves and Nerve Injuries. Edinburgh: E and S Livingstone, 1968:1114-7.

${ }^{2}$ Mumenthaler M, Schliak H. In: Mumenthaler M, Schliak H. Lasionen Peripherer Nerven, Diagnostik and Therapie. Stuttgart: Georg Thieme Verlag, 1977:125-31.

${ }^{3}$ Mulder DW, Dale AJD. In: Baker AB, Baker LH, eds. Clinical Neurology. Hagerstown: Harper \& Row, 1975:1-28.

${ }^{4}$ Aguayo AJ. In: Beeson PB, McDermott W, Wyngaarden JB, eds. Cecil Textbook of Medicine. Philadelphia: WB Saunders, 1979:889-94.

5 Parsonage MJ, Turner JWA. Neuralgic amyotrophy-the shoulder girdle syndrome. Lancet 1948;254:973-8.
${ }^{6}$ Tsairis P, Dyck PJ, Mulder DW. Natural history of brachial plexus neuropathy: report on 99 cases. Arch Neurol 1972:27:109-17.

${ }^{7}$ Magee KR, DeJong RN. Paralytic brachial neuritis. JAMA 1960:174:1258-62.

${ }^{8}$ Hannson KG. Serratus magnus paralysis. Arch Phys Med 1948:29:156-61.

${ }^{9}$ Haymaker W, Woodhall B. In: Haymaker W, Woodhall B. Peripheral Nerve Injuries. Philadelphia: WB Saunders Co., 1953.

${ }^{10}$ Johnson JTH, Kendall HO. Isolated paralysis of the serratus anterior muscle. J Bone Jt Surg 1955:37-A:567-74.

${ }^{11}$ Potts CS. Isolated paralysis of the serratus magnus: report of a case. Arch Neurol Psychiatr 1928:20:184-6.

12 Overpeck DO, Ghormley RK. Paralysis of the serratus magnus muscle. JAMA 1940:114:1194-6.

${ }^{13}$ Horwitz MT, Tocantins LM. Isolated paralysis of the serratus anterior (magnus) muscle. $J$ Bone $J$ t Surg 1938:20:720-5.

${ }^{14}$ Adams RD, Victor M. In: Adams RD, Victor M. Principles of Neurology. New York: McGraw-Hill, 1981 917-22.

${ }^{15}$ Romanes GJ, ed. In: Cunninghams Textbook of Anatomy. Oxford: Oxford University Press, 1981:313-4.

${ }^{16}$ Gray H. In: Gray H, Goss CM, eds. Anatomy of the Human Body. Philadelphia: Lea and Febiger, 1973:454.

${ }^{17}$ Sobotta J, McMurrich JP. In: Atlas Textbook of Human Anatomy. Philadelphia and London: WB Saunders, 1911:216-9.

${ }^{18}$ Dyck PJ, Low PA, Stevens JC. In: Baker AB, Baker LH eds. Clinical Neurology, chap. 51. Hagerstown: Harpeto and Row, 1982:1-126.

${ }^{19}$ Riddoch G, Rowely-Bristow W, Cairns HWB, et al. Aids to the investigation of peripheral nerve injuries. London? Her Majesty's Stationery Office, 1943:4-5.

${ }^{20}$ Spalteholz W. In: Spalteholz W. Hand Atlas of Anatomy Philadelphia: JB Lippincott Co., 1906:721-2.

${ }^{21}$ deJong RN. In: deJong RN. The Neurological Exam: ination. New York: Harper and Row, 1967:456-7.

${ }^{22}$ Horwitz MT, Tocantins LM. An anatomical study of the role of the long thoracic nerve and related scapular bursae in the pathogenesis of local paralysis of the serratus anterior muscle. Anat Rec 1938:71:375-85.

${ }^{23}$ Dargent M. Les nerfs du grand dentele. Annals d'Anat Path Medico Chir 1935:T-12:293.

${ }^{24}$ Hudson AR. In: Wilkins RH, ed. Neurosurgery. New York: McGraw-Hill, 1984 (in press), and personal communication. 